\title{
НАУЧНЫЕ ОСНОВЫ ОРГАНИЗАЦИИ МЕДИКО-СОЦИАЛЬНОЙ ПОМОЩИ ПО ПРОФИЛАКТИКЕ ВНЕМАТОЧНОЙ БЕРЕМЕННОСТИ ЖЕНЩИНАМ ПОЗДНЕГО РЕПРОДУКТИВНОГО ВОЗРАСТА В АМБУЛАТОРНО-ПОЛИКЛИНИЧЕСКИХ УСЛОВИЯХ
}

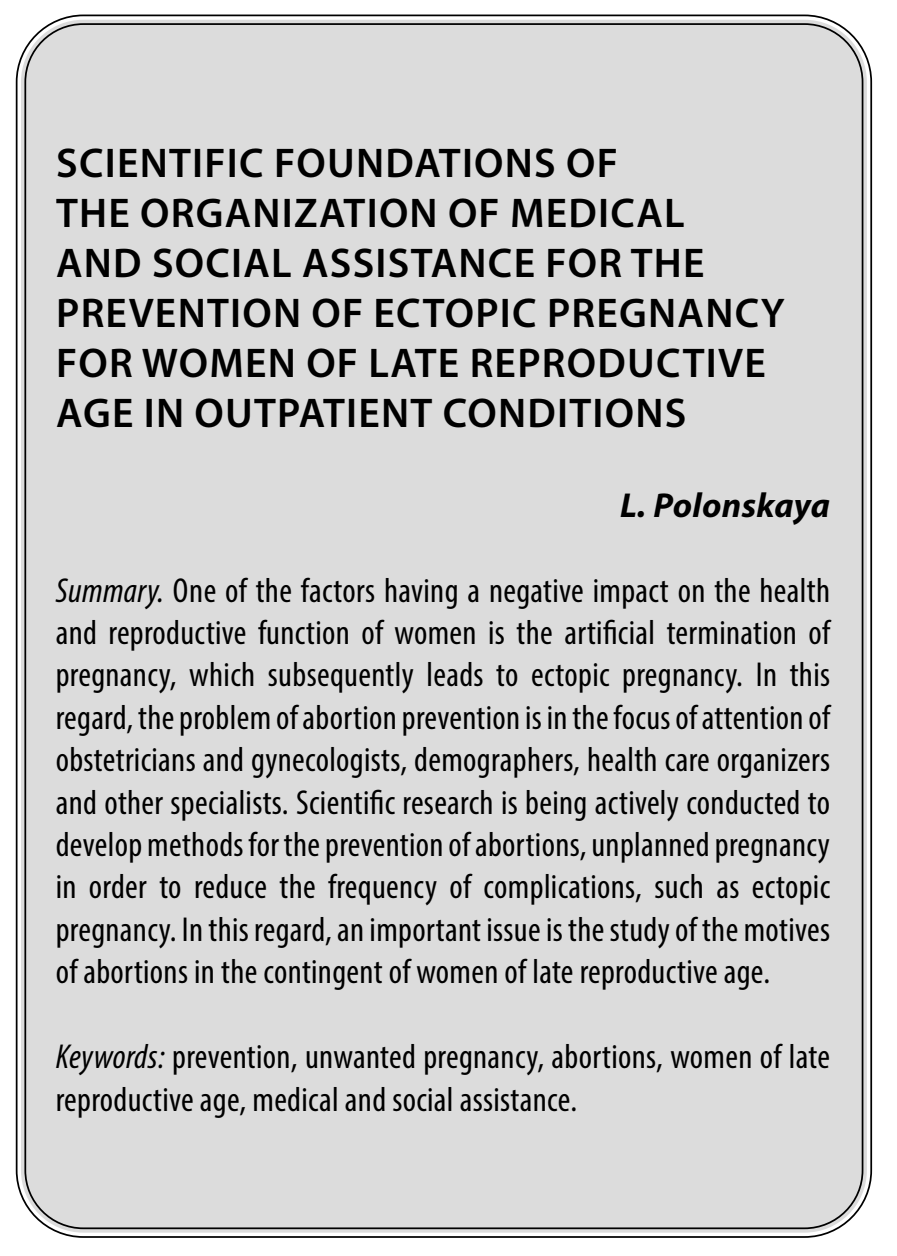

\section{Введение}

B настоящее время имеет место высокий уровень заболеваемости взрослого населения и сохраняется тенденция ее роста, что, в свою очередь, влияет на репродуктивное здоровье мужчин и женщин и, как следствие этого, ухудшается здоровье детей. В связи с этим, оптимизация репродуктивного здороВья населения относится к одной из актуальных и наиболее значимых проблем не только здравоохранения, но и государства в целом». [1, 2, 4]. «Вот почему взгляд на репродуктивное здоровье, как на одну из основ здоровья и главную детерминанту человека, получает все большее признание в мире, однако хорошее репродук-
Полонская Лусине Суреновна

К.м.н., ФГБНУ «Национальный Научноисследовательский институт общественного здоровья имени H.A. Семашко» pollusine@mail.ru

Аннотация. Одним из факторов оказывающим отрицательное влияние на состояние здоровья и репродуктивную функцию женщин является искусственное прерывание беременности приводящее впоследствии к внематочной беременности. В связи с этим проблема профилактики абортов находится в центре внимания акушеров-гинекологов демографов организаторов здравоохранения и других специалистов. Активно ведутся научные исследования по разработке методов профилактики абортов, незапланированной беременности с целью снижения частоты осложнений, как например внематочной беременности. В данной связи важным вопросом является изучение мотивов абортов, в контингенте женщин позднего репродуктивного возраста.

Ключевые слова: профилактика, нежелательная беременность, аборты, женщины позднего репродуктивного возраста, медико-социальная помощь.

тивное здоровье все еще не является достоянием многих людей, как в мире, так и в России $[4,6] . »$.

Репродуктивное здоровье представляет собой состояние полного, душевного и социального благополучия во всех вопросах, касающихся репродуктивной системы, ее функций и процессов, включая воспроизводство и гармонию в психосоциальных отношениях в семье (ВО3, 1994).

Возрастное снижение репродуктивной функции является неизбежным процессом, которое зависит от сочетания как генетических, так и биологических, так и экологических факторов. Однако, в большинстве слу- 


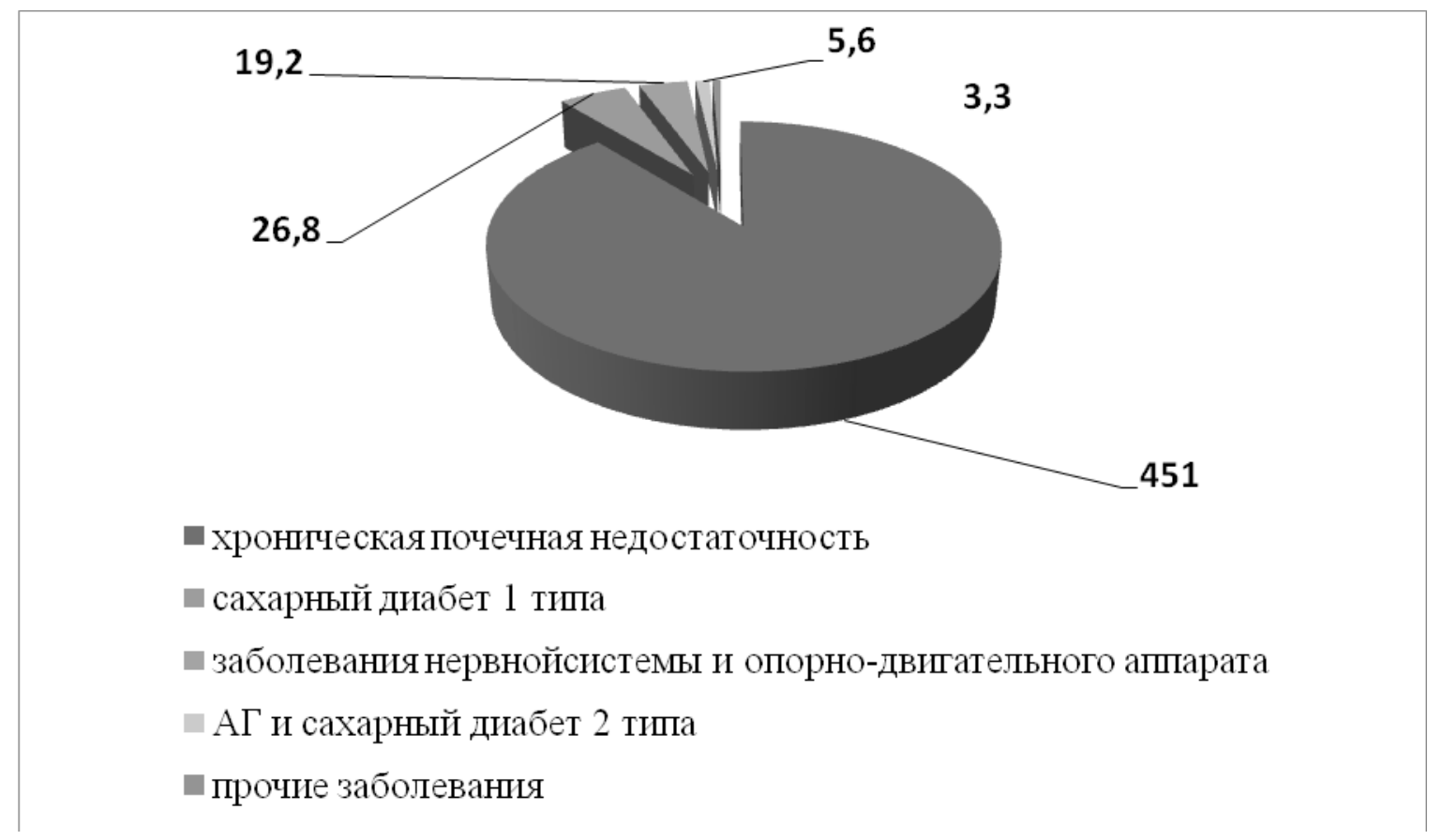

Рис. 1. Структура выявленных основных сопутствующих заболеваний у женщин позднего репродуктивного возраста (в \% к итогу)

чаев, способность к зачатию прекращается с угасанием менструальной функции. Тем не менее, угасанию детородной функции предшествует поздний репродуктивный период, когда женщина ещё может самостоятельно забеременеть, но, в силу каких-либо причин не желает или не имеет возможности этого сделать.

Наименее изученным направлением данной проблемы является организация деятельности амбулаторно-поликлинических учреждений по профилактике внематочной беременности, обоснование оптимальных форм работы акушера-гинеколога в указанном направлении.

\section{Результаты}

В связи с вышеизложенным было проведено исследование 950 женщин позднего репродуктивного возраста с диагнозом в анамнезе внематочная беременHOCTь.

Как показало исследование, у 69,5\% женщин перед возникновением внематочной беременности в анамнезе было 2 или 3 аборта, в основном в возрасте 25-30 лет.

Особого внимания заслуживает группа 40-45- летних женщин, которые решили родить ребёнка впервые и у которых установлена внематочная беременность в связи с наличием абортов в анамнезе в возрасте до 25 лет.
Как показал анализ, большинство женщин начали половую жизнь до 18 лет и имеют вредные привычки: каждая вторая курит, каждая седьмая употребляет алкогольные напитки, имело прерывание первой, самой опасной в плане репродуктивного прогноза, беременности, более половины не используют средства контрацепции, полагаясь на менструальный цикл, почти половина опрошенных женщин не состояла в браке $(46,8 \%)$.

Изучение уровня образования и социального статуса женщин позднего репродуктивного возраста с диагнозом внематочная беременность показало, что большая часть $(65,8 \%)$ имели среднее образование, которые чаще прерывали первую беременность (в 42,3\% случаев) по сравнению с женщинами с высшим образованием и средним специальным (с высшим образованием прерывали первую беременность в 20,1\% случаев, а со средним специальным в 31,5\% случаев).

Следует отметить, что по уровню материального обеспечения большинство женщин $(65,1 \%)$ относились к среднему классу (средний доход на одного члена семьи составляет 15000 рублей), каждая пятая женщина - 20,5\% - относилась к категории богатой по уровню материального благосостояния с доходом на одного члена семьи выше 25000 рублей.

Сами женщины характеризовали условия жизни свои как отличные - 36.8\%; хорошие - 39,5\%; удовлет- 
ворительные - 19.5\% и лишь 4,2\% проживали, по их мнению, в не удовлетворительных бытовых условиях.

Анализ субъективной оценки собственного здоровья показал, что на момент исследования практически здоровыми считали себя 64,3\% женщин позднего репродуктивного возраста; каждая четвёртая (25,3\%) имела экстрагенитальное заболевание; 14,9\% - гинекологическое. Набольшую долю составляли женщины $(4,1 \%)$, имеющие сочетание гинекологического и соматического заболевания.

Бальная оценка состояния здоровья и репродуктивной функции позволили определить, что 46,6\% женщин позднего репродуктивного возраста имеют средние показатели здоровья, формирующиеся в основном за счёт гинекологического анамнеза, отягощённого у $60,1 \%$ женщин неоднократными абортами. Низкие показатели отмечены у 39,9\% женщин. Установлено на момент исследования у каждой из них сочетанная хроническая патология: повышенное артериальное давление в сочетании с хронической почечной недостаточностью в 45,1\% случаев; сахарный диабет 1 типа с повышенным артериальным давлением в 26,8\% случаев; заболевания нервной системы и опорно-двигательного аппарата в 19,2\% случаев и сочетание сахарного диабета 2 типа с артериальной гипертензией в 5,6\% случаев (рис. 1).

Следует отметить также, что хронические гинекологические заболевания такие как эрозия шейки матки, эндометриоз, кольпит, синдром поликистоза яичников выявлены в анамнезе у большинства женщин позднего репродуктивного возраста - 53,6\%, что также является неблагоприятным фактором в качестве прогноза развития внематочной беременности.

Таким образом, на основании данных о состоянии здоровья и репродуктивной функции с учётом комплексной оценки, а также социально-гигиенической характеристики образа жизни женщин позднего репродуктивного возраста можно сделать вывод, что участке врача акушера-гинеколога проживает разнообразный контингент женщин, требующий дифференцированного подхода при оказании амбулаторной акушерско-гинекологической помощи.

При анализе принципов организации и качества мероприятий по профилактике внематочной беременности, структуры применяемой контрацепции, источников информации о факторах риска развития внематочной беременности было установлено, что санитарно-просветительские мероприятия, направленные на сознательное регулирование рождений, проводилось в женских консультациях г. Москвы с 45,2\% контингента женщин позднего репродуктивного возраста, хотя нуждалось в них почти $80,0 \%$.

Медицинская помощь у большинства женщин 57,3\% - при подборе средств контрацепции включала в себя преимущественно сбор анамнеза, осмотр на кресле, лабораторные обследования, консультативная помощь и направление на оздоровление в санаторий. В то же время, эксперты (врачи акушеры-гинекологи) рекомендуют консультировать у врачей специалистов каждую вторую женщину позднего репродуктивного возраста, направлять на лечение гинекологических заболеваний в стационаре каждую третью и оздоровлять в санатории - каждую пятую респондентку.

Важным условием достижения положительных результатов работы акушеров-гинекологов по профилактике внематочной беременности является полный охват необходимыми мероприятиями всех нуждающихся женщин позднего репродуктивного возраста. При этом следует учесть, что на участке имеется определённая группа женщин, нуждающихся в профилактике внематочной беременности, которые или вообще не обращались в женскую консультацию (6,5\%), или с момента их последней явки прошло более одного года (20,8\%), то есть полностью выпадающих из поля зрения врачей акушеров-гинекологов.

Всё вышесказанное приводит к тому, что треть женщин, нуждающихся в профилактике внематочной беременности, не применяет противозачаточные средства с целью регулирования незапланированной беременности и последующих абортов. Причинами этого являются:

- недостаточная осведомлённость о противозачаточных средствах;

- опасение их вредного влияния на гормональный фон женщины;

- сложность и неудобность применения при нерегулярной половой жизни;

- нежелание партнёра;

- чувство стыда при обращении к врачу по подбору противозачаточных средств.

Большинство женщин, наблюдаемых в базовых женских консультациях, используют малоэффективные средства контрацепции, только 15,2\% женщин используют современные средства - внутриматочные спирали и оральные контрацептивы (BMC и ОК), причём только 43,2\% женщин получают информацию о них у врачей, в то время как остальное большинство женщин прибегают к совету знакомых, считая, что в данном вопросе мнение специалистов не важно. Всё это говорит о недостаточной санитарно-просветительской 
работе среди женщин в данном вопросе со стороны самих врачей.

Материалы исследования позволили разработать принципы совершенствования работы женских консультаций, в основу которого положен принцип дифференциации женщин позднего репродуктивного возраста по потребности в профилактике внематочной беременности.

Разнообразие контингента женщин по медико-социальным признакам требует дифференцированного подхода при проведении лечебно-профилактических мероприятий по предупреждению нежелательной беременности и последующих абортах, заключающегося в осуществлении ряда общих, обязательных для всех женщин мероприятиях, таких как сбор анамнеза, осмотр, лабораторно-диагностическое обследование, индивидуальный подбор противозачаточных средств, диспансерное наблюдение, санаторно-просветительские мероприятия, а в ряде случаев других мер, необходимых только для представительниц отдельных групп (оздоровление, лечение, психологическая работа с мужем, родственниками, консультативная помощь).

Данной категории женщин необходимо проводить санитарно-просветительские мероприятия, работу по контрацепции, диспансерное наблюдение дифференцированно в позднем репродуктивном возрасте по характеру, форме, месту, приоритету, кратности мероприятий, а также специалисту, их осуществляющему, соблюдая при этом принцип - чем тяжелее патология и выраженнее влияние неблагоприятных социальных факторов, тем более интенсивному вниманию подлежат женщины.

Одним из факторов, определяющим эффективность профилактической работы, является чёткое выполнение и разграничение функциональных обязанностей между медицинскими работниками женских консультаций, особенно определение места и роли акушерок в проведении полицевого учёта, обеспечении регулярного посещения женщинами врача акушера-гинеколога, проведение санитарно-просветительной работы.

\section{Выво $\triangle \mathrm{b}$}

Как результат проведённого анализа проблемы и выработки тактики профилактической работы с женщинами позднего репродуктивного возраста по профилактике внематочной беременности использован ряд научно обоснованных организационных мероприятий:

- полицевой учёт женского населения;

- активное выявление женщин, нуждающихся в корректировке репродуктивной функции;

- индивидуальные беседы с каждой их них и при необходимости с мужем;

- перед назначением современных противозачаточных средств оздоровление женщины, лечение гинекологических заболеваний.

Все данные мероприятия позволили в течение года увеличить охват женщин позднего репродуктивного возраста современными средствами контрацепции с учётом возрастных изменений в состоянии их здоровья с 35,9\% до 62,1\%; снизить число внематочной беременности с $36,8 \%$ случаев до $25,1 \%$ случаев.

\section{ЛИТЕРАТУРА}

1. Костюкова Н.Б. Медико-социальные аспекты репродуктивного здоровья женщин и пути его повышения: автореф. дис. ... канд. мед. наук. 14.02.03/ Н.Б. Костюкова. - М., 2011. - 22с.

2. Костюкова Н.Б. Прогнозирование состояния репродуктивного здоровья женщин по их медико-социальным характеристикам / Н.Б. Костюкова, Н.В. Наумов, А.В. Демидов // Управление, информация и оптимизация: материалы Всероссийской научной школы.— Воронеж, 2011.— С. 32-34.

3. Машина М.А. Проблемы изменения репродуктивного поведения и реализации репродуктивной функции / М.А. Машина, Е.Н. Шарапова, В.Н. Кузьмин //Медицинский научно-практический журнал «Лечащий врач». - 2014. — № 12. - C. 22-24.

4. Петрова Е.И. Организационные аспекты совершенствования службы родовспоможения региона: автореф. дис. ... канд. мед. наук: 14.02 .03 / Е.И. Петрова.—Рязань, 2014. - 26 с.

5. Нагаев Р.Я. Социально-экономические факторы и здоровье населения / Р.Я. Нагаев, И.М. Бакиев, Т.Ю. Лехмус [и др.] // Здравоохранение и социальное развитие Башкортостана. — 2009.— № 4.—C. 213-216.

6. Нукушева С.Г. Медико-социальные аспекты репродуктивного здоровья женщин в современных условиях: проблемы и пути их решения. - Алматы: «Алем», 2004. - 175 с. 